\title{
Eye movements affect the perception of apparent
}

(beta) movement

JAMES R. POMERANTZ, ${ }^{1}$ Bell Telephone Laboratories, Holmdel, N.J. 07733

When Ss viewed a display in which the apparent direction of illusory movement was ambiguous, they saw movement most often in the direction in which they were instructed to move their eyes. After altering the display in an attempt to reduce its ambiguity, directional eye movements still proved decisive in determining perceived direction. It was concluded that although eye movements are not necessary for the perception of this movement illusion, they can affect its appearance substantially.

When the eye turns to regard a patterned field after prolonged observation of a spinning Archimedes spiral, the $O$ sees a portion of the field expand or contract in the direction opposite to the perceived movement of the spiral. Because the observed expansions and contractions involve simultaneous perception of movement in opposite directions, Dvorak (1870) concluded that eye movements could not account for this illusion of movement. Several subsequent lines of research have supported the extension of this contention to other illusions of movement. Among the more notable of these are Higginson's (1926) finding that beta movement can be perceived in different directions simultaneously over identical regions of the visual field, Guilford \& Helson's (1929) photographs of the eyes during perceptions of phi movement, and Julesz's (1963) study in which apparent movement was perceived under stabilized image conditions. Although the evidence is overwhelming that eye movements are not necessary for the perception of apparent movement, the question remains open as to whether they may affect the form or likelihood of its occurrence. Recently, a study by McFarland (1966) indicated that eye movements may have a powerful effect on a previously unreported type of apparent movement.

Two aspects of the typical stimulus conditions for phi and beta movement should be pointed out. First, the stimuli are usually arranged in such a way that the direction of seen movement is unambiguous. Second, changes of direction of perceived movement, as in simple harmonic motion, are so rapid (e.g., three per second) and so large (usually $180 \mathrm{deg}$ ) as to hinder considerably the eye's attempts at pursuit movements (see Yarbus, 1967). A display of the type described by Wertheimer (1912) and by Higginson (1926) has neither of these characteristics. In one of its simpler forms, $a+$ is presented alternately with a copy of itself, rotated through $45 \mathrm{deg}$ arranged with their intersections coincident; i.e., if they were presented simultaneously, the two shapes would appear as one figure with eight equally spaced arms. When the shapes were presented alternately, however, Os reported seeing one four-armed figure that, at different times, appeared to move in four distinct ways: It may spin clockwise (CW), spin counterclockwise (CCW), rock back and forth, or "flap its arms" without rotating as a unit. Higginson reported that Os of this display would see the type of movement that they were instructed to see, but he offered no suggestion about the way that control over the perceptual response was mediated. Earlier, Wertheimer had asserted that "set and posture of attention [p. 1070]" decided the perceptual outcome. The present study tested the hypothesis that eye movements determine the type of movement seen with a display of this kind.

\section{METHOD}

The display used is shown in Fig. 1. The duration of each stimulus was set at $100 \mathrm{msec}$, and the intervals between them were $25 \mathrm{msec}$ each; thus, the figure

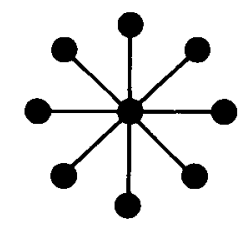

A

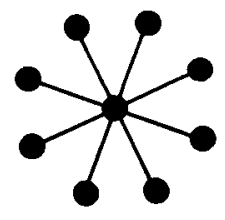

B

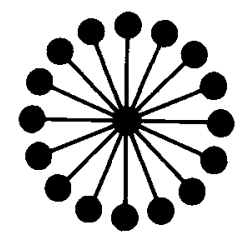

c

Fig. 1. (a) The stimulus presented in the first channel. (b) A copy of (a) rotated through $22.5 \mathrm{deg}$ presented in the second channel. (c) How (a) and (b) would appear if presented simultaneously. The stimuli subtended a visual angle of approximately $30 \mathrm{deg} 20 \mathrm{~min}$. appeared to spin at $.5 \mathrm{rps}$, a comfortable speed for tracking. The stimuli were drawn on white illustration board with a No. 4 nib Rapidograph pen and black Rapidograph Universal ink. The stimuli were presented in two channels of a four-channel tachistoscope described elsewhere (Kolers, 1962), and the intervals between them appeared as a lighted blank screen. Six Ss, employees of Bell Telephone Laboratories, Inc., who were unpracticed in vision experiments, looked at the display with the right eye only.

Three different sets of instructions were given to each of the six Ss in counterbalanced order. The instructions were: (1) Fixate the center of the figure; (2) move eyes around the figure $\mathrm{CW}$; (3) move eyes around the figure $\mathrm{CCW}$. Three Ss responded by activating a timer switch whenever $\mathrm{CW}$ movement was seen, and the other three responded when $\mathrm{CCW}$ movement was seen. Test periods for viewing lasted $1 \mathrm{~min}$. All Ss served in three sessions of six test periods each, two test periods under each of the three instruction conditions. Before beginning their tests on the first day, all Ss were shown the test display tachistoscopically. Without prompting, all Ss reported seeing $\mathrm{CW}$ and $\mathrm{CCW}$ rotation, and most reported the "arm flapping" movement. When asked to judge the speed of rotation, all Ss gave a figure very near .5 rps.

\section{RESULTS}

Table 1 shows the percentage of time during the test periods that Ss reported seeing the specified type of rotary movement. The effect of instructions was significant $[F(2,8)=9.32, \quad p<.01]$, showing that Ss most often saw movement in the same direction as their eye movements, and that they least often saw movement in the direction opposite to eye movement. The effect of sessions was significant $[F(2,8)=4.89, p<.05]$ and the Instructions by Sessions interaction just failed to reach significance $[F(4,16)=2.96, p>.05]$. There were no other significant sources of variance.

What were the Ss actually seeing during the test periods? Postexperimental comments from the Ss indicate that when they moved their eyes in the same

Table 1

Per Cent Time Rotary Movement was Seen in the Specified Direction Under Three Types of Eye Movement Instructions for Three Sessions

\begin{tabular}{|c|c|c|c|}
\hline \multirow{2}{*}{$\begin{array}{l}\text { Eye Movement } \\
\text { Instructions }\end{array}$} & \multicolumn{3}{|c|}{ Sessions } \\
\hline & 1 & 2 & 3 \\
\hline Same Direction & 64.8 & 72.7 & 82.5 \\
\hline Fixate Center & 37.3 & 41.8 & 43.9 \\
\hline Opposite Direction & 30.2 & 29.2 & 25.2 \\
\hline
\end{tabular}


direction as that to which they were to respond to perceived movement, Ss tended to track one of the disks on the end of an arm as it rotated about the center of the figure; occasionally, however, the direction of rotation would reverse spontaneously for a few seconds. Furthermore, Ss reported that under the fixation condition, changes in perceived direction of rotation were frequent, with $\mathrm{CW}$ and $\mathrm{CCW}$ movement being seen for equivalent total durations. "Flapping" movement was seen with the greatest frequency under this condition.

\section{DISCUSSION}

It is assumed, in the absence of contradictory information, that Ss moved their eyes as they were instructed to do. Hence, the results of the present study indicate that eye movements affect the perceived direction of movement of an ambiguous stimulus. To show that eye movements are capable of helping the visual system resolve an ambiguity does not demonstrate that they can have any effect on the perception of a nonambiguous stimulus situation. That is to say, the possibility may be entertained that eye movements normally play a minor, imperceptible role in determining perceived direction of apparent movement, and that it is only in the completely ambiguous situation in which the visual system is at a loss for decisive data that directional eye movements can be shown to be effective. To pursue this question, an informal experiment was conducted with similar figures in which the stimulus in the second channel (see Fig. 1) was rotated $11.5 \mathrm{deg}$ further so that now, when presented simultaneously, the composite figure appeared to have eight pairs of arms rather than 16 equally spaced ones. Now, it is well known that, all other things being equal, apparent movement is more easily perceived over shorter distances. It was thought, therefore, that this configuration would lead to a single and unambiguous perception of an eight-armed figure in a rucking rotary motion. In fact, the ambiguity of the display was only very slightly reduced, and no decrease in the effect of eye movements on perceived direction of rotation was observed; a rigid figure is still most often seen, again rotating in the direction consistent with eye movements.

The means by which this directional component of eye motion enters into and affects the construction of the percept is not clear in the case of apparent movement, although a number of studies in the tradition of the sensory-tonic theory of perception and the reafference and efference theories of perception have described analogous results.
One explanation views eye movements as serving to keep a portion of the figure, say one of the disks, centered on the fovea in much the same manner as tracking operates in the perception of real movement; in this case, however, the foveal image is, of course, temporally discontinuous. Motion is then ascribed to the disk by eye-movement feedback or command signals. This clue regarding the movement of one part of the figure could act to resolve the ambiguity of the entire display's movement, thus forcing the observed perception of a single rigid figure rotating.

An alternative interpretation regards eye movements as but one type of motor activity that may have an effect on the percept. Burnham (1969) has shown that when three-dimensional figures are rotating with ambiguous direction, rotary movements of the arm in one direction leads to a more stable percept of movement in that same direction. Comparing the magnitude of the effect of directional motor activity in Burnham's study (near 12\%) with that in the present study (near $61 \%$ ) suggests, if not compels, the conclusion that eye movements should not be classified together with other forms of motor activity with reference to their effect on visual perception.

Another interesting aspect of the phenomenon, but on which measurements were not made, was the spontaneous reversals in the perceived direction of movement, also reported by Higginson. It remains as a speculation whether these reversals are truly spontaneous or are to be attributed to momentary changes in direction of the O's eye movements. Flicks and saccades have already been suggested as one component in a movement illusion (Schouten, 1967); momentarily regressive eye movements may also have occurred in this experiment to alter the perceived direction of object motion. Should that be the case, eye movements would be shown to have a larger role than has hitherto been suspected in shaping percepts.

\section{REFERENCES}

BURNHAM, C. A. Consistency between motor activity and perceived direction of rotation. Perception \& Psychophysics, 1969, 5, 29-32.

DVORAK, V. Versuche über die Nachbilder von Reizveränderung. Sitzungsber. Akademie Wissenschaft Wien, math.-naturw. Cl., 1870, 61, 257-262. Cited in E. G. Boring, Sensation and perception in the history of experimental psychology. N e w York: Appleton-Century-Crofts, 1942.

GUILFORD, J. P., \& HELSON, H. Eye movements and the phi-phenomenon. American Journal of Psychology, 1929, 51, 595-606.

HIGGINSON, G. D. Apparent visual movement and the Gestalt. Journal of Experimental Psychology, 1926, 9, 228-252.

JULESZ, B. Effects of contour flicker or apparent motion on retinally stabilized images. Journal of the Optical Society of America, 1963, 53, 1336 (abstract).

KOLERS, P. A. Multi-field electronic apparatus for studies of visual perception. Report No. MRL-TDR-62-33, 1962, Wright-Patterson Air Force Base.

McFARLAND, J. H. The influence of eye movements on a new type of apparent visual movement. Psychonomic Science, 1966, 4, 51-52.

SCHOUTEN, J. F. Subjective stroboscopy and a model of visual movement detectors. In $W$. Wathen-Dunn (Ed.), Models for the perception of speech and visual form. Cambridge: M.I.T. Press, 1967. Pp. 44-45.

WERTHEIMER, M. Experimentelle Studien über das Sehen von Bewegung. Zeitschrift für Psychologie, 1912, 61, 161-265. In T. Shipley (Ed.), Classics in psychology. New York: Philosophical Library, 1961. Pp. 1032-1089. YARBUS, A. L. Eye movements and vision. New York: Plenum Press, 1967. NOTE

1. The author thanks Paul A. Kolers, Bela Julesz, and John Krauskopf for their suggestions and comments. 